\title{
Cancer distribution pattern in south-western Nigeria
}

\author{
OLUFUNSHO AWODELE ${ }^{*}$, AYOKUNLE A. ADEYOMOYE², DEBORAH F. AWODELE ${ }^{3}$, VINCENT \\ B. FAYANKINNU 4 and DURO C. DOLAPO 5 \\ ${ }^{1}$ Department of Pharmacology, College of Medicine, University of Lagos, Nigeria \\ 2Department of Radiation Biology, Radiodiagnosis ERadiotherapy, College of Medicine, University of Lagos, \\ Nigeria \\ ${ }^{3}$ School of Midwifery, Lagos University Teaching Hospital, Lagos, Nigeria \\ ${ }^{4}$ School of Health Information Management, Lagos University Teaching Hospital, Lagos, Nigeria \\ ${ }^{5}$ Department of Community Health, Lagos University Teaching Hospital, Lagos, Nigeria
}

\begin{abstract}
The burden of cancer in Nigeria is appreciable with about 100,000 new cancer cases being reported in the country each year. This study aimed to determine the level of occurrence and pattern of distribution of different cancer types in two major functional cancer registries in south-western Nigeria. A desk review of the level of occurrence and pattern of distribution of different cancer types in Lagos and Ibadan cancer registries over a 5 year period (2005-2009) was carried out. The results obtained showed a total number of 5094 cancer patients registered between 2005 and 2009 in both Lagos $(60 \%)$ and Ibadan $(40 \%)$ cancer registries. Breast cancer accounted for the majority of cases (20.2\%), followed by cervical cancer (7.9\%), fibroid (4.4\%), liver $(4.4 \%)$, stomach $(4.3 \%)$, brain $(3.9 \%)$, pancreas $(3.8 \%)$, prostate $(3.3 \%)$, lung $(3.0 \%)$ and cancer of the kidney $(0.7 \%)$. There were significant differences $(P \leq 0.05)$ in the level of occurrence between cancers of the breast, cervix, prostate, liver, ovary and all other cancers. Liver cancer $(147 ; 77)$ and bone cancer $(91 ; 37)$ were predominant in females than males while lung cancer $(89 ; 65)$, stomach cancer $(112 ; 109)$, and kidney cancer $(24 ; 14)$ were predominant in males than females. In conclusion, the findings of this study provide insights to cancer epidemiology in the western region of Nigeria. This study confirms earlier findings that breast, prostate, liver and cervical cancers account for the majority of cases of cancers in Nigeria. Thus, there is need to organize on a wider scale suitable methods for early detection of these diseases.
\end{abstract}

Key words: cancer, types, distribution, Nigeria

\section{Introduction}

Cancer which is one of the most dreaded non-communicable diseases has become an important contributor to the global burden of diseases. The burden of cancer is growing, and it is one of the leading causes of death worldwide (Binu et al., 2007). There are more than 100 types of cancer and their symptoms vary widely (Adebamowo \& Ajayi, 2000). Globally, approximately 10 million people are diagnosed with cancer annually (Stewart \& Kleihues, 2003). The increase of cancer incidence is occurring at a faster rate of $48 \%$ in developed countries and $52 \%$ in developing countries (Parkin et al., 1993). With increasing industrialization and westernization of dietary and other socio-behavioural attitudes in most developing countries, it is estimated that the burden of cancer will increase to epidemic proportions in twenty-first century (Okobia, 2003). Deaths from cancer in the world are projected to continue to rise, with an estimated nine million people expected to die from cancer in 2015 and 11.4 million in 2030 (WHO, 2007a,b). The cancer epidemiological report in Africa showed 667,000 incident cases and 518,000 deaths in 2008 (Boyle \& Levin, 2008).

The burden of cancer in Nigeria is appreciable. According to the World Health

*Correspondence: Olufunsho Awodele; E-mail: awodele@yahoo.com 
Organization, 100,000 new cancer cases are being reported in the country each year, although different observers believe the figure could become as high as 500,000 new cases annually by 2010 (Ogundipe \& Obinna, 2008). It may be projected that by 2020, cancer incidence for Nigerian males and females may rise to $90.7 / 100,000$ and $100.9 / 100,000$, respectively. In Nigeria, with a population of nearly 140 million people, complex diseases such as cancer are currently emerging as important health care priority for the future. The subsequent attendant increase in life expectancy is likely to lead to an increase in the incidence of all types of cancers, as a higher proportion of the population reaches the complex diseases-bearing age (Adebamowo \& Ajayi, 2000; Anyawu, 2000).

There are two major functional cancer registries in south-western Nigeria; Ibadan Cancer Registry at University College Hospital, Ibadan and Lagos Cancer Registry at Lagos University Teaching Hospital, Lagos. Although, some hospitals in south-western Nigeria have screening programmes for cervical cancer, but these programmes are poorly funded, unsystematic and not comprehensive. Most of these cancer registries data are not routinely collected and published. Information on incidence, prevalence, pattern and high risk factors are essential to plan, implement and to evaluate control of cancer. But this information is not readily available for most of the developing countries (Binu et al., 2007; Boyle \& Levin, 2008) may be due to limited number of cancer registries, attitude of people to health facilities utilization, level of education of people, poverty and poor record keeping. It may thus be necessary to determine the level of occurrence and pattern of distribution of different cancer types in two major functional cancer registries in south-western Nigeria.

\section{Materials and Methods}

\section{Study area}

The sources of data were Ibadan Cancer Registry at University College Hospital, Ibadan and Lagos Cancer Registry at Lagos University Teaching Hospital, Lagos in Nigeria. Lagos University Teaching Hospital is one of the largest teaching hospitals in Nigeria. It is located in Lagos State which is a state in south-western Nigeria. Lagos is one of Nigeria's most populated states. It is the chief port, principal economic and cultural centre. The teaching hospital has 761 bed spaces and records over 9,000 patient attendances in a month. University College Hospital Ibadan is one of the oldest and largest teaching hospitals in West Africa region with approximately 600 bed spaces. It is located in Oyo state in southwestern Nigeria. Ibadan is the largest city in Nigeria.

\section{Data collection and analysis}

This was a retrospective desk review of registers of the level of occurrence and pattern of distribution of different cancer types in Lagos and Ibadan cancer registries over a 5 year period (2005-2009). A standard data collection tool was used to obtain socio-demographic information (sex, marital status and location), type of cancer and year of diagnosis. The data obtained from this study were analyzed using the Epi-Info 2002 software programme. The data was presented in frequency distribution tables with percentages and Chi square analysis was used to test the significance at $\mathrm{p} \leq 0.05$. 


\section{Ethical considerations}

An ethical permission was obtained from the record units of the institutions of the studied areas to obtain data on level of cancer occurrence and cancer distribution pattern in their cancer registries.

\section{Results}

A total number of 5094 cancer patients were registered between 2005 and 2009 in both Lagos $(60 \%)$ and Ibadan $(40 \%)$ cancer registries. Males and females accounted for $64.5 \%$ and $35.5 \%$ of the patients, respectively. Some $63 \%$ (3211) of the patients were married. There were 857 $(16.8 \%)$ patients in 2005, $871(17.1 \%)$ in 2006, $788(15.5 \%)$ in 2007, $1046(20.5 \%)$ in 2008 and $1532(30.1 \%)$ in 2009 . Breast cancer had the highest percentage (20.2\%), followed by cervical cancer $(7.9 \%)$, fibroid $(4.4 \%)$, liver $(4.4 \%)$, stomach $(4.3 \%)$, brain $(3.9 \%)$, pancreas $(3.8 \%)$, prostate $(3.3 \%)$, lung $(3.0 \%)$ and the cancer of the kidney was the lowest type $(0.7 \%)$

Table 1: The frequency (\%) of cancer by type and sex

\begin{tabular}{llllll}
\hline Cancer types & Male & Female & Total & $\chi^{2}$ & P-value \\
\hline Abdominal & $74(4.1)$ & $70(2.1)$ & $144(2.8)$ & 16.44 & 0.0001 \\
Bone & $91(5.0)$ & $37(1.1)$ & $128(2.5)$ & 72.88 & 0.00 \\
Brain & $109(6.0)$ & $90(2.7)$ & $199(3.9)$ & 33.78 & 0.00 \\
Breast & $64(3.5)$ & $965(29.3)$ & $1029(20.2)$ & 481.56 & 0.00 \\
Cervical & NA & $403(12.3)$ & $403(7.9)$ & 240.37 & 0.00 \\
Colon & $66(3.7)$ & $128(3.9)$ & $194(3.8)$ & 0.18 & 0.67 \\
Connective and soft tissue & $90(5.0)$ & $83(2.5)$ & $173(3.4)$ & 21.49 & 0.00 \\
Ductal & $65(3.6)$ & $161(4.9)$ & $226(4.4)$ & 4.63 & 0.03 \\
Eye & $103(5.7)$ & $69(2.1)$ & $172(3.4)$ & 46.43 & 0.00 \\
Fibroid & NA & $226(6.9)$ & $226(4.4)$ & 129.90 & 0.00 \\
Kidney & $14(0.8)$ & $24(0.7)$ & $38(0.7)$ & 0.03 & 0.86 \\
Leukaemia & $73(4.0)$ & $85(2.6)$ & $158(3.1)$ & 8.23 & 0.004 \\
Liver & $147(8.1)$ & $77(2.3)$ & $224(4.4)$ & 93.21 \\
Lung & $65(3.6)$ & $89(2.7)$ & $154(3.0)$ & 3.17 & 0.00 \\
Non-hodkins lymphoma & $48(2.7)$ & $49(1.5)$ & $97(1.9)$ & 8.51 & 0.08 \\
Ovary & NA & $155(4.7)$ & $155(3.0)$ & 87.81 \\
Pancreas & $94(5.2)$ & $101(3.1)$ & $195(3.8)$ & 14.41 \\
Prostate & $169(9.4)$ & NA & $169(3.3)$ & 318.24 \\
Stomach & $109(6.0)$ & $112(3.4)$ & $221(4.3)$ & 19.42 \\
Others & $425(23.5)$ & $364(11.1)$ & $789(15.5)$ & 138.31 \\
Total & $\mathbf{1 8 0 6 ( 1 0 0 )}$ & $\mathbf{3 2 8 8 ( 1 0 0 )}$ & $\mathbf{5 0 9 4 ( 1 0 0 )}$ & 0.004 \\
\hline NA-Not & & & & 0.000 \\
\end{tabular}

NA- Not applicable

Breast cancer was registered in 3.5\% (64) and 29.3\% (965) of male and female patients, respectively, out of the 1029 total patients. Liver cancer $(147 ; 77)$ and bone cancer $(91 ; 37)$ were predominant in female than male while lung cancer $(89 ; 65)$, stomach cancer $(112 ; 109)$, kidney cancer $(24 ; 14)$ were predominant in male than female (Table 1$)$. There were significant differences $(P \leq 0.05)$ in the level of occurrence between cancers of the breast, cervix, prostate, liver, ovary and all other cancers (Table 1). Most of the studied cancers; cervical $(235 ; 168)$, breast $(718 ; 311)$, abdominal $(84 ; 60)$, liver $(126 ; 98$,$) lung (114 ; 40)$, ovary $(79 ; 76)$, prostate $(121 ; 48)$, stomach $(141 ; 80)$ predominantly occurred in married patients than single patients. Only the bone cancer $(77 ; 51)$ was observed to occur in single patients 
than married patients. There were significant differences $(P \leq 0.05)$ between cancers of the breast, cervix, prostate, fibroid, ovary and all other cancers (Table 2).

Table 2: Frequency (\%) of cancer type by marital status

\begin{tabular}{|c|c|c|c|c|c|}
\hline \multirow{2}{*}{ Cancer type } & \multicolumn{3}{|c|}{ Frequency (\%) } & \multirow{2}{*}{$\chi^{2}$} & \multirow[t]{2}{*}{ P-value } \\
\hline & Single & Married & Total & & \\
\hline Abdominal & $60(3.2)$ & $84(2.6)$ & $144(2.8)$ & 1.41 & 0.24 \\
\hline Bone & $77(4.1)$ & $51(1.6)$ & $128(2.5)$ & 30.31 & 0.00 \\
\hline Brain & $86(4.6)$ & $113(3.5)$ & $199(3.9)$ & 3.47 & 0.06 \\
\hline Breast & $311(16.5)$ & $718(22.4)$ & $1029(20.2)$ & 25.15 & 0.00 \\
\hline Cervical & $168(8.9)$ & $235(7.3)$ & $403(7.9)$ & 4.19 & 0.04 \\
\hline Colon & $71(3.8)$ & $123(3.8)$ & $194(3.8)$ & 0.01 & 0.91 \\
\hline Connective and soft tissue & $86(4.6)$ & $87(2.7)$ & $173(3.4)$ & 12.49 & 0.0004 \\
\hline Ductal & $72(3.8)$ & $154(4.8)$ & $226(4.4)$ & 2.65 & 0.10 \\
\hline Eye & $62(3.3)$ & $110(3.4)$ & $172(3.4)$ & 0.07 & 0.80 \\
\hline Fibroid & $46(0.8)$ & $180(5.6)$ & $226(4.4)$ & 28.01 & 0.00 \\
\hline Kidney & $15(3.7)$ & $23(0.7)$ & $38(0.7)$ & 0.10 & 0.75 \\
\hline Leukaemia & $69(3.7)$ & $89(2.8)$ & $158(3.1)$ & 3.15 & 0.08 \\
\hline Liver & $98(5.2)$ & $126(3.9)$ & $224(4.4)$ & 4.63 & 0.03 \\
\hline Lung & $40(2.1)$ & $114(3.6)$ & $154(3.0)$ & 8.23 & 0.004 \\
\hline Non-hodkins lymphoma & $40(2.1)$ & $57(1.8)$ & $97(1.9)$ & 0.78 & 0.38 \\
\hline Others & $292(15.5)$ & $497(15.5)$ & $789(15.5)$ & 0.001 & 0.98 \\
\hline Ovary & $76(4.0)$ & $79(2.5)$ & $155(3.0)$ & 9.99 & 0.002 \\
\hline Pancreas & $86(4.6)$ & $109(3.4)$ & $195(3.8)$ & 4.43 & 0.04 \\
\hline Prostate & $48(2.5)$ & $121(3.8)$ & $169(3.3)$ & 5.50 & 0.02 \\
\hline Stomach & $80(4.2)$ & $141(4.4)$ & $221(4.3)$ & 0.06 & 0.81 \\
\hline Total & $1883(100)$ & $3211(100)$ & $5094(100)$ & & \\
\hline
\end{tabular}

Table 3: Distribution frequency (\%) of cancer type by cancer registry location

\begin{tabular}{llllll}
\hline Cancer type & Lagos & Ibadan & Total & $\chi^{2}$ & P-value \\
\hline Abdominal & $90(2.9)$ & $54(2.6)$ & $144(2.8)$ & 0.40 & 0.53 \\
Bone & $49(1.6)$ & $79(3.9)$ & $128(2.5)$ & 25.68 & 0.00 \\
Brain & $117(3.8)$ & $82(4.0)$ & $199(3.9)$ & 0.12 & 0.73 \\
Breast & $814(26.7)$ & $215(10.4)$ & $1029(20.2)$ & 197.02 & 0.00 \\
Cervical & $273(8.9)$ & $130(6.4)$ & $403(7.9)$ & 11.06 & 0.001 \\
Colon & $93(3.0)$ & $101(5.0)$ & $194(3.8)$ & 12.13 & 0.001 \\
Connective and soft tissue & $115(3.8)$ & $58(2.8)$ & $173(3.4)$ & 3.17 & 0.08 \\
Ductal & $123(4.0)$ & $103(5.0)$ & $226(4.4)$ & 3.01 & 0.08 \\
Eye & $121(4.0)$ & $51(2.5)$ & $172(3.4)$ & 8.01 & 0.01 \\
Fibroid & $49(1.6)$ & $177(8.7)$ & $226(4.4)$ & 144.27 & 0.00 \\
Kidney & $9(0.3)$ & $29(1.4)$ & $38(0.7)$ & 20.98 & 0.00 \\
Leukaemia & $111(3.6)$ & $47(2.3)$ & $158(3.1)$ & 7.21 & 0.01 \\
Liver & $102(3.3)$ & $122(6.0)$ & $224(4.4)$ & 20.28 & 0.00 \\
Lung & $71(2.3)$ & $83(4.1)$ & $154(3.0)$ & 12.69 & 0.0004 \\
Non-hodkins lymphoma & $51(1.7)$ & $46(2.3)$ & $97(1.9)$ & 2.24 & 0.14 \\
Others & $472(15.5)$ & $317(15.5)$ & $789(15.5)$ & 0.01 & 0.94 \\
Ovary & $81(2.7)$ & $74(3.6)$ & $155(3.0)$ & 3.94 & 0.05 \\
Pancreas & $102(3.3)$ & $93(4.6)$ & $195(3.8)$ & 4.94 & 0.03 \\
Prostate & $100(3.3)$ & $69(3.4)$ & $169(3.3)$ & 0.04 & 0.83 \\
Stomach & $111(3.6)$ & $110(5.4)$ & $221(4.3)$ & 9.10 & 0.003 \\
Total & $\mathbf{3 0 5 4 ( 1 0 0 )}$ & $\mathbf{2 0 4 0 ( 1 0 0 )}$ & $\mathbf{5 0 9 4 ( 1 0 0 )}$ &
\end{tabular}

Most of the cancer types were recorded in the Lagos registry than Ibadan registry. Abdominal cancer (90), brain cancer (117), breast cancer (814), cervical cancer (273), ovary 
cancer (81) and prostate cancer (100) were recorded more frequently in Lagos than Ibadan (Table 3). However, some of the cancer types like bone cancer $(49 ; 79)$, Colon (93; 101), Fibroid cancer $(49 ; 177)$, Liver cancer $102 ; 122)$, Kidney cancer $(9 ; 29)$ and Lung cancer $(71$; $83)$ occurred more in Ibadan cancer registry than Lagos registry.

There were significant differences $(P \leq 0.05)$ between cancers of the breast, cervix, fibroid, ovary and all other cancers. Most of the cancers were diagnosed in 2009. However, ductal cancer had highest diagnosis of 57 patients in 2008 as against the 53 diagnosed patients in 2009 out of the 226 total patients. The cancer of the kidney recorded highest diagnosis of 10 patients in 2005 as against 9 patients in 2009 out of the 38 patients. Sixtythree patients had liver cancer in 2008 while 59 patients were diagnosed in 2009 (Table 4).

Table 4: Frequency (\%) of cancer type by year of diagnosis

\begin{tabular}{lllllllll}
\hline Cancer type & $\mathbf{2 0 0 5}$ & $\mathbf{2 0 0 6}$ & $\mathbf{2 0 0 7}$ & $\mathbf{2 0 0 8}$ & $\mathbf{2 0 0 9}$ & Total & $\chi^{\mathbf{2}}$ & P-value \\
\hline Abdominal & $19(2.2)$ & $30(3.4)$ & $25(3.2)$ & $30(2.9)$ & $40(2.6)$ & $144(2.8)$ & 2.98 & 0.56 \\
Bone & $13(1.5)$ & $20(2.3)$ & $24(3.0)$ & $30(2.9)$ & $41(2.7)$ & $128(2.5)$ & 5.26 & 0.26 \\
Brain & $42(4.9)$ & $34(3.9)$ & $27(3.4)$ & $41(3.9)$ & $55(3.6)$ & $199(3.9)$ & 3.15 & 0.53 \\
Breast & $192(22.4)$ & $175(20.1)$ & $125(15.9)$ & $150(14.3)$ & $387(25.3)$ & $1029(20.2)$ & 58.41 & 0.00 \\
Cervical & $87(10.2)$ & $82(9.4)$ & $62(7.9)$ & $62(5.9)$ & $110(7.2)$ & $403(7.9)$ & 15.38 & 0.004 \\
Colon & $30(3.5)$ & $42(4.8)$ & $26(3.3)$ & $37(3.5)$ & $59(3.9)$ & $194(3.8)$ & 3.44 & 0.49 \\
Connective tissue & $30(3.5)$ & $37(4.2)$ & $28(3.6)$ & $34(3.3)$ & $44(2.9)$ & $173(3.4)$ & 3.37 & 0.50 \\
Ductal & $32(3.7)$ & $45(5.2)$ & $39(4.9)$ & $57(5.4)$ & $53(3.5)$ & $226(4.4)$ & 8.56 & 0.07 \\
Eye & $21(2.5)$ & $22(2.5)$ & $32(4.1)$ & $43(4.1)$ & $54(3.5)$ & $172(3.4)$ & 7.15 & 0.13 \\
Fibroid & $41(4.8)$ & $42(4.8)$ & $30(3.8)$ & $50(4.8)$ & $63(4.1)$ & $226(4.4)$ & 1.96 & 0.74 \\
Kidney & $10(1.2)$ & $8(0.9)$ & $3(0.4)$ & $8(0.8)$ & $9(0.6)$ & $38(0.7)$ & 4.35 & 0.36 \\
Leukaemia & $20(2.3)$ & $30(3.4)$ & $27(3.4)$ & $40(3.8)$ & $41(2.7)$ & $158(3.1)$ & 5.04 & 0.28 \\
Liver & $34(4.0)$ & $33(3.8)$ & $35(4.4)$ & $63(6.0)$ & $59(3.9)$ & $224(4.4)$ & 8.81 & 0.07 \\
Lung & $18(2.1)$ & $23(2.6)$ & $30(3.8)$ & $38(3.6)$ & $45(2.9)$ & $154(3.0)$ & 5.94 & 0.20 \\
N-lymphoma & $13(1.5)$ & $15(1.7)$ & $17(2.2)$ & $26(2.5)$ & $26(1.7)$ & $97(1.9)$ & 3.36 & 0.50 \\
Others & $142(16.6)$ & $125(14.4)$ & $118(15.0)$ & $168(16.1)$ & $236(15.4)$ & $789(15.5)$ & 2.06 & 0.73 \\
Ovary & $28(3.3)$ & $30(3.4)$ & $28(3.6)$ & $35(3.3)$ & $34(2.2)$ & $155(3.0)$ & 5.17 & 0.27 \\
Pancreas & $25(2.9)$ & $25(2.9)$ & $45(5.7)$ & $45(4.3)$ & $55(3.6)$ & $195(3.8)$ & 12.56 & 0.01 \\
Prostate & $31(3.6)$ & $24(2.8)$ & $27(3.4)$ & $35(3.3)$ & $52(3.4)$ & $169(3.3)$ & 1.16 & 0.89 \\
Stomach & $29(3.4)$ & $29(3.3)$ & $40(5.1)$ & $54(5.2)$ & $69(4.5)$ & $221(4.3)$ & 6.86 & 0.14 \\
Total & $\mathbf{8 5 7}$ & $\mathbf{8 7 1}$ & $\mathbf{7 8 8}$ & $\mathbf{1 0 4 6}$ & $\mathbf{1 5 3 2}$ & $\mathbf{5 0 9 4}$ & \\
\hline
\end{tabular}

\section{Discussion}

WHO reports that cancer is the second commonest cause of mortality after cardiovascular diseases. However, data about the prevalence of cancer in Nigeria like elsewhere in Africa is scarce as only $7.2 \%$ of the population is covered by cancer registries (Akinwande et al., 2009). The present study may be the first of its kind to be conducted on the pattern of cancers in south-western Nigeria. Epidemiological information on cancer including the pattern is an important basis for determining the priorities for cancer control in any population group. There are marked differences in distribution of cancers in different regions of the world (Pisani, 1994). Environmental and socio-cultural factors such as active and passive tobacco smoking, use of non-smoking tobacco, alcohol intake, exposure to ultraviolet rays, dietary factors, pollutants of air, water and soil contribute to the development of different types of cancers (Page \& Asire, 1985; Satariano \& Swanson, 1988; Stewart \& Kleihues, 2003; Binu et al., 2007). However, this present study could not access some of the environmental and 
socio-cultural factors of the patients as only the cancer registries registers were used for this study.

The data obtained revealed that female patients had a higher percentage of cancers in the study areas, which is not consistent with the earlier study of Binu et al., (2007) who showed higher male patients with cancer than female in Nepal. This may be due to curiosity of the females about their health than male counterpart which will eventually lead to more attendance in the clinic. It may also be due to increasing cases of breast, cervical and fibroid cancers as shown in this study. This finding is consistent with the findings by other authors (Adebamowo \& Ajayi, 2000; Madong et al., 2003; Adefuye, 2006) who showed that cancer of the cervix is the commonest genital tract malignancy in the female and ranked second to breast cancer. Although, cancers of cervix and breast are common among women in most of the developing countries as earlier stated, the later is the specific leading cancer in women in the developed countries (Stewart \& Kleihues, 2003).

It has been established in this study that cancer cases are commoner in married patients. This observation may be due to remarkable association of some studied cancers (breast, cervical and prostate) with age (Battikhi, 2003), child bearing (Tretli \& Haldorsen, 1990) and sexual intercourse (Akinwande et al., 2009). The highest cases of cancers in year $2009(30.1 \%)$ as against the earlier years may be due to increase level of health education among people in south-western Nigeria to undergo cancer screening as early detection is important for good management of cancers. Presently there are quite a number of institutional based breast and cervical cancer screening activity in Nigeria.

It has been shown in this study that more proportion of cancers is found in Lagos cancer registries than Ibadan cancer registries. This finding may be due to the dense population in Lagos and some environmental factors such as vehicular emission, tobacco smoke, carcinogenic chemicals and industrial pollution which are commoner in Lagos. However, it cannot be concluded that all registered patients in Lagos cancer registry were from Lagos. There were significant differences between the level of occurrence of breast, cervical, prostate cancers and other forms of cancers. Similar findings have been reported by others (Adebamowo \& Ajayi 2000; Madong et al., 2003; Adefuye, 2006; Awodele et al., 2009) that showed the high rate of breast and cervical cancers compared with other cancers.

In conclusion, the cancer pattern revealed in this study provides valuable insights to cancer epidemiology in the western region of Nigeria. Breast, prostate, liver and cervical cancers are the most frequent cancer in the area. Thus, there is need to organize on a wider scale suitable methods for early detection of these diseases. Studies like this present one may also provide useful information for health planning and future research.

\section{Acknowledgements}

The authors sincerely thank Prof C.A Adebamowo, of the University College Hospital, Ibadan-Nigeria for providing relevant information used in this study.

\section{References}

Adebamowo, C.A. \& Ajayi O.O. (2000) Breast cancer in Nigeria. West African Journal Medicine $19,179-194$ 
Adefuye, P.O. (2006) Knowledge and practice of cervical cancer screening among female professional health workers in a sub-urban district of Nigeria. Nigerian Medical Practitioner 50, 19-22

Akinwande, O., Ogundiran, T., Akarolo, S.A, Mamadu, I., Dakum, P., Blattner, W., \& Adebamowo, C. (2009) Challenges in Treating Malignancies in HIV in Nigeria. Current Opinion in Oncology 21, 455-461.

Awodele, O., Adeyomoye, A.A.O, Oreagba, I.A, Dolapo, D.C, Anisu, D.F, Kolawole, S.O, Ishola, I.O, Adebayo, K.A. \& Akintonwa, A. (2009) Knowledge, attitude and practice of breast cancer screening among nurses in Lagos University Teaching Hospital, LagosNigeria. Nigerian Quarterly Journal of Hospital Medicine 19, 114-118

Battikh, M.N.G. (2003) Age-specific reference ranges for prostate-specific antigen (PSA) in Jordanian patients. Prostate Cancer and Prostatic Diseases 6, 256-260.

Binu, V.S, Chandrashekhar, T.S, Subba, S.H. (2007) Cancer pattern in Western Nepal: a hospital based retrospective study. Asian Pacific Journal of Cancer Prevention 8, $183-$ 186.

Boyle, P., \& Levin, B., (2008) World Cancer Report, Geneva. International Agency for Research on Cancer.

Madong, B.M, Madaka, A.K.J. \& Mannaseh, A.N. (2003) Malignant disease in Jos: a follow up. Annals of African Medicine 2, 28-53.

Ogundipe, S., \& Obinna, C. (2008) Nigeria: Why cancer is on the rise in the country. Vanguard Newspaper report, http://allafrica.com/stories/200806170258.html

Okobia, M.N. (2003) Cancer care in Sub-saharan Africa- Urgent need for population-based cancer registries. Ethiopian Journal of Health Development 17(2), 89-98

Page, H.S, \& Asire, A.J. (Eds) (1985) Cancer Rates and Risks. 3rd ed., Washington DC: US Department of Health and Human Services, 85-91.

Parkin, D.M, Freddie, M.D, Ferlay, J. \& Paola, P. (2005) Global cancer statistics. Cancer Journal for Clinician 55, 74-108.

Pisani, P., (1994) Burden of cancer in developing countries. IARC Scientific Publications, 129 IARC Lyon, 31-39.

Satariano, W.A. \& Swanson, G.M. (1988) Racial differences in cancer incidence: the significance of age specific patterns. Cancer 62, 2640-53.

Stewart, B. W. \& Kleihues, P. (Eds.). (2003) World Cancer Report. Lyon, France: International Agency for Research on Cancer. www.scribd.com/.../World-Cancer-Report

Tretli S \& Haldorsen T (1990). A cohort analysis of breast cancer, uterine corpus cancer, and childbearing pattern in Norwegian women. Journal of Epidemiology Community Health 44(3), 215-219

WHO (2007a) WHO web site http://www.who.int/mediacentre/ factsheets/fs297/en/index.html.

WHO (2007b) WHO calls for prevention of cancer through healthy workplaces. wwww.who.int http://www.who.int/mediacentre/news/notes/2007/np19/en/index.html. 